\title{
Insulin Treatment, Type 2 Diabetes and Obesity
}

\author{
Elisabeth Govers* \\ Knowledge Centre for Dietitians on Overweight and Obesity, Netherlands
}

Submission: November 14, 2017; Published: November 21, 2017

*Corresponding author: Elisabeth Govers, Knowledge Centre for Dietitians on Overweight and Obesity, Amsterdam, Cornelis van Alkemadestraat 16; 1065 AC Amsterdam, Netherlands, Email: e.govers112@upcmail.nl

\section{Introduction}

Of all patients with type 2 diabetes mellitus an estimated $85 \%$ has overweight or obesity. It is well documented that obesity leads to type 2 diabetes after a long period of insulin resistance. For patients weight loss becomes harder when the amount of medication increases. Especially the use of sulfoneum derivates and, or insulin makes weight loss fairly impossible, since medication that promotes the release of insulin creates the opposite effect, which is weight gain. Patients often find it frustrating that they rather gain than lose weight. For these patients we developed a regime of a low carbohydrate diet combined with a reduction of insulin to make weight loss possible. Hereby two patient cases are presented to show results that can be obtained by this therapy.

\section{Patient 1}

A forty four year old morbidly obese woman was referred by the nurse practitioner because of an ill regulated type 2 diabetes. She, a mother of three, had stopped metformin because of extensive intestinal problems. Her fasting glucose was $260 \mathrm{mg} /$ $\mathrm{dL}(14 \mathrm{mmol} / \mathrm{l})$; and GlyHb was $80 \mathrm{mmol} / \mathrm{mol}$. She used daily 3x35 IU fast-acting insulin and 78 IU of a long-acting insulin. Body weight was 138 kilos and BMI was $45.1 \mathrm{~kg} / \mathrm{m} 2$. Recently she went through a severe case of pneumonia which had brought her to realize that she had to do something about her health and lifestyle. She was accompanied by her husband who had to lose weight as well. She was clear about the fact that she would like to lose weight. She was informed of the low carbohydrate approach, which she had tried once before herself. She was also informed that if weight loss would not occur, she could, according to the guideline, enrol in a bariatric surgery procedure.

At the intake the dietary history made clear that her carbohydrate intake was extensive: 150 grams from bread, fruit, and a cooked meal with white rice, pasta or potatoes. In the afternoon and evening she would snack wine gums, cookies and crisps, an additional estimate of 100grams of carbohydrates per day. Once or twice per week the cooked meal was replaced by pizza or Chinese take away. She did not have any exercise at all. She had a stressful job at the local police station.

After the principles and rationale of the diet were explained, being that insulin resistance is the underlying problem, causing glucose values to rise all the time, regardless of the insulin levels taken; and that the only way to escape from this situation is to bring the carbohydrate intake down to minimum levels, and lower the insulin intake dependent on the glucose levels. She accepted the fact that all meals would be low carbohydrate, high protein, and she started off with a diet where she could take 36 grams of carbohydrates spread over 6 eating moments. A complicating factor was the fact that she was proven to be lactose intolerant. The first two weeks she would monitor her glucose values before each meal, and once a day before going to sleep, write the results down. If she would perceive low glucose values $<130 \mathrm{mg} / \mathrm{dL}(<7 \mathrm{mmol} / \mathrm{l})$ before bedtime, she would lower the long-acting insulin. The fast-acting insulin was not to be lowered yet, because of the high GlyHb and fasting glucose values. If anything out of the ordinary would occur, she could phone me at any given time. At the second visit she was very cheerful: she had been able to lower the long-acting insulin from 78 to 38 IU. Her husband, who was very supportive throughout the treatment, and managed to lose 25 kilos in 7 months, and she had decided not to buy any pizza's or take away. Non fasting glucose was $150 \mathrm{mg} / \mathrm{dL}(8 \mathrm{mmol} / \mathrm{l})$ average.

At every visit she wanted to have new recipes for evening meals. Insulin went down to 15 IU before breakfast, and 5IU before the other meals; 38 IU before sleeping. After four weeks we decided to lower long-acting insulin further with 2 IU per time, dependent on evening glucose values, because weight loss stopped. Two weeks after, she lost three kilo's more. Body weight was after six weeks 126 kilos, BMI $41.1 \mathrm{~kg} / \mathrm{m} 2$. After 2 months she told me her weight loss target was $100 \mathrm{kilos}$, and surgery was no option. Insulin was lowered to $15 \mathrm{IU}$ in the morning and $8 \mathrm{IU}$ before sleeping. She had picked up exercise: cycling and swimming twice a week. We kept 2-4 weeks visits to monitor weight loss 
and discuss diet and life style and occurring problems, such as her desire to eat candy, which she fought successfully up to now. She allowed herself low carb bread although glucose values went up more after eating that. The same thing happened when she ate fruit or candy. Because of her motivation to lose weight she was able to refrain from eating candy, although she also came to realize that her desire for sweet food was stress or fatigue related: when things were hard at work, she felt more need to take candy. After nine months her body weight was 99kilo's, BMI $32.2 \mathrm{~kg} / \mathrm{m} 2$. GlyHb dropped to $46 \mathrm{mmol} / \mathrm{mol}$. Insulin is $15 \mathrm{IU}$ short-acting insulin in the morning and 8 IU long-acting insulin before sleeping. Fasting glucose is $160 \mathrm{mg} / \mathrm{dL}$ ( $9 \mathrm{mmol} / \mathrm{l}$ ); before the evening meal glucose is $110 \mathrm{mg} / \mathrm{dL}(6 \mathrm{mmol} / \mathrm{l})$. She is still on track and has set her weight target at 90 kilos.

\section{Patient 2}

A sixty seven year old woman, with insulin dependent type 2 diabetes mellitus and an extensive patient history with treated myocardial infarction, mama carcinoma, kidney failure and schizophrenia, expressed the desire to lose weight. She gained 10 kilos since the last three years and was especially concerned about her expanding belly. Her fasting glucose varied between $150-230 \mathrm{mg} / \mathrm{dL}$ ( 8.2 and $12.6 \mathrm{mmol} / \mathrm{l}$ ); before dinner glucose was $150-270 \mathrm{mg} / \mathrm{dL}$ (8.7 to $15.1 \mathrm{mmol} / \mathrm{l}$ ). GlyHb was $80 \mathrm{mmol} / \mathrm{mol}$; waist circumference 127 centimetres; weight 105 kilo's and BMI $35.5 \mathrm{~kg} / \mathrm{m} 2$. Her medication consisted besides medication for blood pressure and heart failure of psycho pharmaca (Anastrosal) and intermediate-acting insulin: 54 IU in the morning and $60 \mathrm{IU}$ in the evening before dinner. The main problem was the glucose level that was unpredictable: even if she ate very little carbohydrates the glucose levels could be for above limits. We discussed the matter, and I saw as most probable cause that my patient administered the insulin in affected needle marks, preventing the insulin form entering the blood stream. We agreed she would take the insulin in her upper legs subcutaneously instead of in her belly. When she changed the glucose levels dropped immediately, causing a onetime hypoglycaemia. Insulin was lowered to $44 \mathrm{IU}$ at breakfast and 40 IU in the evening. She started to lose weight, first to $102 \mathrm{~kg}$, waist circumference lowered to $122 \mathrm{~cm}$.

The dietary history had revealed that her diet consisted mainly of carbohydrates, about 175grams per day. In the treatment it was hard to explain to her that she had to take as little carbohydrates as possible; the amount was set on 75 grams. From time to time she would take a glass of fruit juice which made the glucose levels go up immediately, over $180 \mathrm{mg} / \mathrm{dL}(0 \mathrm{mmol} / \mathrm{l})$. She then would take $4 \mathrm{IU}$ insulin extra to bring glucose down to acceptable levels, preventing weight loss that way. It frustrated her a great deal, until she understood: she could lower the insulin intake by 2 IU per time. She told me she was scared of the high glucose values. From that moment on she realised the glucose values corresponded with the consumption of the juice she had more confidence and was able to lower insulin to twice a day $28 \mathrm{IU}$ after two months. Fasting glucose was $130-150 \mathrm{mg} /$ dL (7-8.5mmol/l); weight 99.9 kilos; BMI $31.3 \mathrm{~kg} / \mathrm{m} 2$ and WC $121 \mathrm{~cm}$.

After six months treatment insulin was two times $20 \mathrm{IU}$ per day, weight 92.8 kilos and WC $115 \mathrm{~cm}$. total weight loss so far 12 kilos; loss of waist circumference was 12 centimetres. Insulin intake lowered from 114 IU to 40 IU per day; fasting glucose is $130 \mathrm{mg} / \mathrm{dL}(7 \mathrm{mmol} / \mathrm{l})$; GlyHb was $51 \mathrm{mmol} / \mathrm{l}$. The patient is very happy with her weight loss and her loss of waist circumference. She wants to continue the program to lose more weight. She has learnt how to keep to the diet and does so every day. The most significant change was however in her personality. At the intake she was unorganised and had problems getting her life back on track. During the six months, she became increasingly coherent and developed more initiative to take care of her house and her appearance, and she started to walk daily.

\section{Conclusion}

Weight loss is possible in obese patients with insulin dependent type 2 diabetes mellitus. In fact, it is an option that should be seriously considered if patients are obese, take large quantities of insulin and still have high glucose values and GlyHb. Patients that finally lose weight and have good glucose values are motivated to improve their health further. One of the implications is that due to the better glucose values they feel more energetic, and less tired. That helps them to get their life better organised. Through this treatment quality of life improves for these patients. An additional advantage is that medicine costs lower considerably through this approach.

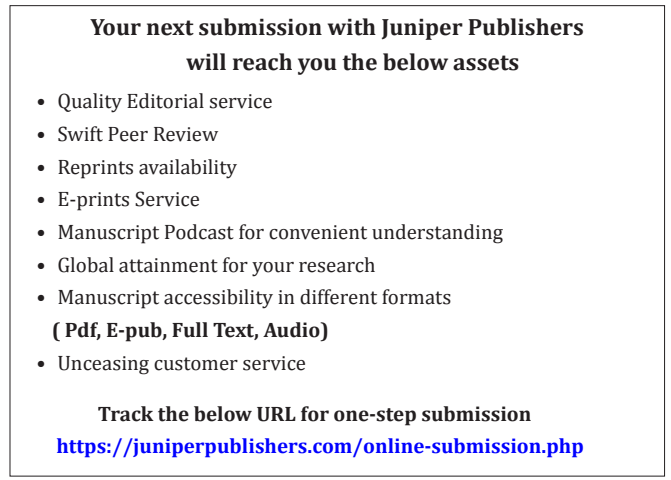

